\title{
Miles Iaponus et Christianus: Japanische Märtyrer auf der Jesuitenbühne
}

\author{
Mirjam Döpfert
}

\section{Historischer Überblick zur Japanmission: das , christliche Jabrhundert '(1549-1638)}

1549 läutete der Jesuitenpater Franz Xaver mit seiner Ankunft in Japan das sogenannte christliche Jahrhundert ein. ${ }^{1}$ Schon bald nach Beginn der Mission gab es Massentaufen zu vermelden, die sicherlich nicht allein auf den Heilswillen der Bevölkerung gegründet waren: Die Japaner zeigten reges Interesse am Handel mit den Portugiesen, auf deren Schiffen die Jesuiten das ,Land der aufgehenden Sonne' erreichten. Die Zahl der neugetauften Christen (Neophyten) nahm stetig zu und stieg zwischen 1600 und 1610 auf rund 500.000. ${ }^{2}$ Zugleich wuchs jedoch auch das christenfeindliche Klima in Japan. Gründe hierfür waren unter anderem die Angst vor dem wachsenden Einfluss Spaniens und Portugals sowie die Handelskonkurrenz durch die calvinistischen Niederländer, die nicht missionierten. Ferner stand das Christentum in der Kritik, da es sich nicht mit der japanischen Lehenspyramide vereinbaren ließ. ${ }^{3}$ So wurde Ende des 16. Jahrhunderts das erste Verbannungsedikt gegen Missionare verkündet und 1614 unter dem Shogun Ieyasu erneuert, der im Rahmen einer grausamen Christenverfolgung die Missionare des Landes verwies, Kirchen zerstörte und Neophyten zum Glaubensabfall zwang oder ermorden ließ. So starben bis 1631 etwa 1.200 Christen den Märtyrertod. Nach 1637 begab sich das Land schließlich in die komplette Isolation, um jeglichen Einfluss von außen abzuwehren.

Diese Ereignisse blieben Europa nicht verborgen - vermittelt wurden sie über die Jahresbriefe der Jesuitenmissionare, die litterae annuae, die in vielen Ländern zirkulierten. Die Christen, die in Japan ihr Leben für den Glauben ließen, gingen

1 Vgl. hierzu Arcadio Schwade: Die Frühgeschichte des Christentums in Japan im Überblick. In: Ruprecht Wimmer und Adrian Hsia (Hg.): Mission und Theater (Jesuitica; 7). Regensburg 2005, 289-353.

2 Vgl. Günther Jontes: Japonenses Martyres. Japanische Stoffe im Grazer Jesuitentheater des 16. und 17. Jahrhunderts. In: Historisches Jabrbuch der Stadt Graz 15, 1984, 27-52, hier 35.

3 Vgl. Claudia von Collani: Helden, Heiden und Märtyrer. Ostasien im deutschen Jesuitentheater. In: Christel Meier und Angelika Kemper (Hg.): Europäische Schauplätze des frühneuzeitlichen Theaters. Normierungskräfte und regionale Diversität (Schriftenreihe des Sonderforschungsbereichs 496: Symbolische Kommunikation und gesellschaftliche Wertesysteme vom Mittelalter bis zur französischen Revolution; 34). Münster 2011, 369-416, hier 373 und 389. Thomas Immoos: Japanische Helden des europäischen Barocktheaters. In: Maske und Kothurn 27: 1, 1981, 36-56, hier 37. 
in jesuitische Missions- und Kirchengeschichten ${ }^{4}$ sowie Martyrologien $^{5}$ ein, und ihre Geschichten wurden nicht zuletzt auch in Form von Flugblättern und Predigtexempeln einer breiten Bevölkerungsschicht zugänglich gemacht (Abb. 1). ${ }^{6}$ Bald schon erreichten die Japanstoffe auch die Bühnen des Jesuitentheaters und wurden dort kontinuierlich gespielt. Im deutschen Sprachraum lässt sich die erste Aufführung auf das Jahr 1604 oder $1607^{7}$ datieren. Bis zur Aufhebung des Ordens im Jahre 1773 gelangten mehr als 280 Japandramen zur Aufführung, wovon die große Mehrheit - mehr als zweihundert Dramen - den japanischen Märtyrern gewidmet war.

Für die Popularität des Märtyrersujets ${ }^{8}$ sind mehrere Gründe ins Feld zu führen: Als fester Bestandteil des jesuitischen Schulsystems war das Theater ein Medium, den katholischen Glauben und das Wertesystem der Jesuiten zu vermitteln. Die Bühne diente als Kanzel, die Schüler und Publikum zu einer christlichen Lebenspraxis animieren und den Siegeszug des katholischen Glaubens (ecclesia triumphans) propagieren sollte. Die Märtyrerfigur eignete sich hierfür besonders, lieferte sie doch ein eindrückliches exemplum fidei. Das Publikum sollte dabei weniger direkt zum Martyrium aufgerufen werden, als vielmehr zur imitatio einer Glaubenstreue, die sich gerade auch in Extremsituationen bewähren muss, ja im äuBersten Fall bis in den Tod als letzte Konsequenz.

Das Interesse an dem unbekannten und daher als ,exotisch' markierten Land Japan sowie die Aktualität des dortigen Missionsgeschehens verhalfen den japanischen Märtyrern zu Attraktivität. Darüber hinaus jedoch brachte das exotische Setting einen weiteren Vorteil mit sich: Es ermöglichte den Jesuiten, die katholische Kirche als weltweit agierende Institution zu präsentieren, deren Missionserfolge

4 Zum Beispiel Nicolas Trigault: DE CHRISTIANIS APVD IAPONIOS | TRIVMPHIS | SIVE DE GRAVISSIMA IBIDEM CONTRA CHRISTI | FIDEM PERSECVTIONE EXORTA | ANNO MDCXII | VSQUE AD ANNVM MDCXX | LIBRI QUINQUE. München 1623. Cornelius Hazart: KERCKELYCKE | HISTORIE | VAN DE | GHEHEELE WERELDT, | NAMELYCK VANDE VOORGAENDE | ENDE | TEGHENWOORDIGHE EEVWE. 4 Bde. Antwerpen 1671.

5 Zum Beispiel Mathias Tanner: SOCIETAS | JESU | USQUE AD | SANGUINIS | ET VITAE PROFUSIONEM | MILITANS, | IN EUROPA, AFRICA, ASIA | ET AMERICA, | CONTRA | GENTILES, MAHOMETANOS, | JUDAEOS, HAERETICOS, | IMPIOS, | PRO | DEO, FIDE, | ECCLESIA, | PIETATE. | SIVE | VITA ET MORS | EORUM, | Qui | Ex Societate Jesu in causa FIDEI \& Vir- | tutis propugnatae, violentâ morte toto Orbe sublati sunt. Prag 1675.

6 Vgl. hierzu Claudia von Collani: Jesuitisches Schrifttum als Quellenfundus der China-JapanDramen. In: Ruprecht Wimmer und Adrian Hsia (Hg.): Mission und Theater (Jesuitica; 7). Regensburg 2005, 259-288.

7 Das älteste, nicht genau datierbare Japandrama De Japoniorum martyris stammt laut JeanMarie Valentin aus Graz: Jean-Marie Valentin: Le théatre des Jésuites dans le pays de langue Allemande. Répertoire chronologique des pièces représentées et du documents conservés (1555-1773), Bd. 1. Stuttgart 1983, 65, Nr. 576.

8 Auch aus der Missionsgeschichte in anderen fernen Ländern (beispielsweise China, Amerika, Indien) wurden Märtyrer auf die Jesuitenbühne gebracht, quantitativ jedoch dominieren die japanischen; vgl. Immoos: Japanische Helden (Anm. 3), 36. 


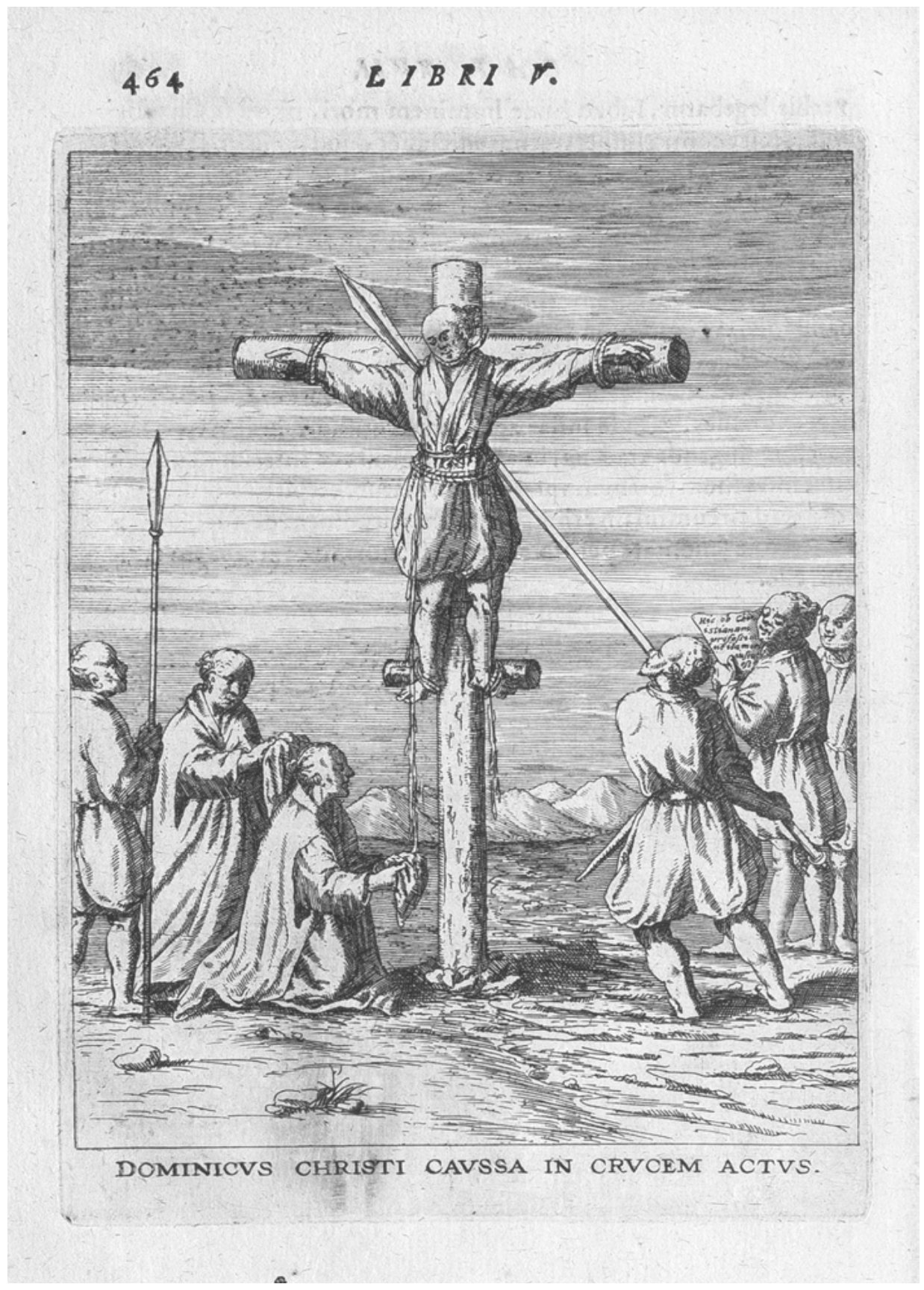

Abb. 1: Martyrium des Dominicus Catzo als Postfiguration Christi, Kupferstich. In: Nicolas Trigault: DE CHRISTIANIS APVD IAPONIOS | TRIVMPHIS [...]. München 1623, 464, Wolfenbüttel, Herzog August Bibliothek, A: 197 Hist. 
den Beweis lieferten für den auf ihr ruhenden himmlischen Segen. ${ }^{9}$ Die Japonica sind in diesem Zusammenhang theatrum mundi im doppelten, im wörtlichen wie im metaphorischen Sinne. Die vielen Märtyrer in Übersee präsentierten die katholische Kirche als ecclesia afflicta, als bedrängte Kirche im Sinne des Neuen Testaments. Zugleich verdeutlichten sie im Kontext des „konfessionellen Wettrüstens“, 10 dass die katholische Kirche die Märtyrertradition fortführte und damit die einzige legitime Nachfolgerin der Alten Kirche war. Gerade weil die katholische Kirche im Laufe der Reformationsbewegung in vielen europäischen Territorien an Einfluss verloren hatte, affirmierte sie mit ihren Erfolgen in den überseeischen Gebieten ihren Anspruch auf geistliche und weltliche Vorherrschaft. ${ }^{11}$

Da die meisten der Jesuitendramen nicht vollständig überliefert wurden, ${ }^{12}$ basieren die folgenden Beobachtungen zur Präsenz des ,Fremden' in den japanischen Märtyrerdramen auf der Analyse sogenannter Periochen. Diese im Vorfeld der Aufführungen ausgehändigten Inhaltszusammenfassungen (von gr. $\pi \varepsilon \rho \iota \varepsilon ́ \chi \varepsilon t v:$ ,umfassen $\left.{ }^{6}\right)^{13}$ sollte den lateinunkundigen Zuschauern ein Verständnis des Bühnengeschehens erleichtern. ${ }^{14}$ Sie liefern zwar nur knappe Inhaltsbeschreibungen, geben jedoch einen guten Überblick über die jeweilige Dramenstruktur.

9 Der Hinweis auf die Missionserfolge diente natürlich auch dazu, finanzielle, materielle und personelle Mittel für die Mission zu werben; vgl. Collani: Helden, Heiden und Märtyrer (Anm. 3), 379.

10 Peter Burschel: Sterben und Unsterblichkeit. Zur Kultur des Martyriums in der Frühen Neuzeit (Ancien Régime, Aufklärung und Revolution; 35). München 2004, 221, der in seiner Studie auch die Martyrologien von Täufern und Protestanten untersucht. Beispiele für solche Martyrologien sind die Werke des Luther-Schülers Ludwig Rabus (Historien | Der Heyligen Außer- | wölten Gottes Zeügen / Bekennern vnd | Martyrern / so in Angehender ersten Kirchen / | Altes vnd Neüwes Testaments / zuo | jeder zeyt gewesen | seind [...]. Straßburg 1552), des Anglikaners John Foxe (ACTES | and Monuments | of these latter and perillous dayes [...]. London 1563) und des Calvinisten Jean Crespin (HISTOIRE | des vrays Tesmoins de la veri- | TE DE L'EVANGILE [...]. Genf 1570).

11 Die Insel Japan wird dabei als Ersatz für die nicht länger katholische Insel England angesehen: „Aber nimb war du liebe Christenheit / Was Waffen [...] an derselben einigen Engelländischen Jnselstatt / ein andere / Ja viel Jnseln / Königreich / vnnd [...] abgesönderte Völcker zu dir getretten." (Gaspar Coelho: Jüngste Zeytung auß der weitberümbten Insel Jappon [...]. Dillingen 1586. Zitiert nach Peter Kapitza: Japan in Europa. Texte und Bilddokumente zur europäischen Japankenntnis von Marco Polo bis Wilhelm von Humboldt, Bd. 1. München 1990, 146).

12 Es wurden bisher nur wenige Handschriften ausfindig gemacht. Da die Dramen nur für eine einmalige Aufführung konzipiert waren, lohnte es sich nicht, sie in Druck zu geben. Ausnahmen sind Dramen berühmter Autoren wie Gretser, Bidermann, Masen oder Avancini.

13 Diese meist zweisprachig verfassten Texte enthalten neben Titel, Aufführungsort und -datum ein Argumentum (Einordnung in zeitlichen Kontext, knappe Zusammenfassung der Handlung, meist Hinweis auf Stoffquelle), eine Paraphrase der jeweiligen Szenen und den Syllabus actorum, der die Namen der Spieler verzeichnet. Der Name des Dramenautors wird nicht aufgeführt, seine Person tritt bewusst hinter dem Ruhm Gottes zurück: Die Formel „omnia ad maiorem Dei (Deiparaeque) gloriam“ (O.A.M.D.(D.)G.) beschließt jede Perioche.

14 Vgl. Elida Maria Szarota: Das Jesuitendrama im deutschen Sprachgebiet, Bd. 1.1: Vita bumana und Transzendenz. München 1979, 8. Allerdings konstatiert Wimmer, dass die Periochen lediglich unter den (lateinkundigen) Honoratioren verteilt wurden: Ruprecht Wimmer: 


\section{Inszenierung von Fremdheit in den japanischen Märtyrerdramen}

Bei der Handlungskonzeption sahen sich die jesuitischen Autoren mit einem Dilemma konfrontiert: Auf der einen Seite profitierten die Japonica von der ,Exotik', die mit dem fremden Land und seiner reichen Kultur verbunden war. Auf der anderen Seite jedoch mussten der Erwartungshorizont des Publikums bedient und das Identifikationspotenzial der Helden sichergestellt werden. Die Lösung lag in einem ästhetischen Kompromiss. Man betonte das exotische Setting ${ }^{15}$ und transferierte das ,Fremde ${ }^{6}$ der japanischen Kultur verstärkt auf die heidnischen Gegenspieler der Märtyrer. Das ,Eigene' erscheint in diesem Zusammenhang verengt auf das katholische Christentum, ${ }^{16}$ das dem (japanischen) teuflischen Heidentum als ,Fremdem' gegenübergestellt wird. Das Bestreben, eine potenzielle Andersartigkeit der japanischen Christen zu negieren, wird bereits in der Namensgebung evident: Wo die Namen der Heiden und ihrer Götter japanisch sind, ${ }^{17}$ tragen die japanischen Christen ihren europäischen Taufnamen. Auf der Handlungsebene tritt dieses Phänomen jedoch noch deutlicher hervor. Wird hier Fremdheit thematisiert, geschieht dies hauptsächlich im religiösen Kontext.

Neuere Forschungen zum Jesuitentheater des deutschen Sprachbereiches: Ein Bericht (1945-1982). In: Daphnis 12: 4, 1983, 585-692, hier 689, Anm. 537.

Auf der Ebene der Darstellung wurde die Exotik wahrscheinlich über Bühnenbild, Requisiten und Kostümierung auf die Bühne gebracht, wovon es leider keine druckgrafischen Zeugnisse gibt.

16 Innerhalb der Bühnenhandlung finden sich - soweit die Periochen dies erkennen lassen nur wenige Hinweise auf kulturelle Eigenheiten, die nicht im Zusammenhang mit der heidnischen Religion stehen. So wird zum Beispiel im Argumentum des Dramas FUGA, | INNOCENTIAE | PERICLITANTIS | ASYLUM, | In Augustino Principe | Chicungensi | Spectata (Konstanz 1744) der Stellenwert des Haares in der japanischen Kultur hervorgehoben, als Augustinus sich in einer Geste der Weltentsagung die Haare abschneidet: „formosissimum sibi continuò capillum, quo nil à Japoniis majus praestari, efficique potest, praescidit“ (sinngemäße Übersetzung: ,unmittelbar darauf schnitt er sich sein wunderschönes Haar ab, als das nichts mehr gilt bei den Japanern und als das nichts Bedeutenderes bewirkt werden kann'). Im Drama IEMON | INVICTUS CHRISTI MARTYR (Straubing 1661) gibt das Argumentum an: „Uber ein kurz liesse der Fürst die Kriegs ristung von Iemone abhollen / welches bey den Iaponeseren für ein grosse Schand gehalten wird“. Auch gibt es einige in die Handlung integrierte Fechtszenen, in denen die japanische Schwertkunst vorgeführt werden konnte, zum Beispiel TITVS IAPON. | TRAGICOCOMOEDIA (Augsburg 1629), II 4. Die Reflexion aktueller politischer Kontexte findet kaum Eingang in die Japonica. Die Ausnahme bildet hier die TITUS |TRAGOEDIA aus Luzern (1735), welche die Angst Japans vor einer Vormachtstellung Portugals thematisiert: Hier werden beim Christen Gonsalvus (wohl von seinem Gegenspieler Saffojus gefälschte) Briefe gefunden, die besagen, dass Japan an die Portugieser verraten werden soll (III 7).

17 Diese werden meist benannt als Amida/Amata, Chamis, Fotoquis oder Xaca/Xacca. Zur Herkunft dieser Götternamen vgl. Jontes: Japonenses Martyres (Anm. 2), 36 und 38. 


\subsection{Heidentum und Komik}

In vielen Dramen werden Feiern für die heidnischen japanischen Götter in Szene gesetzt, ${ }^{18}$ über deren inhaltliche und bühnentechnische Ausgestaltung aufgrund der Kürze der Paraphrasen keine Rückschlüsse gezogen werden können. Allerdings werden sie in manchen Periochen deutlich gewertet. So heißt es in einer Szenenbeschreibung des Rottweiler TITVS IAPON: „[Die Bontzen] fangen ein newe Hunds-metten an / mit abenthewrischen Gaugelwerck “. ${ }^{19}$ Ein Tanz des Dramas CLEMENS JAPON (Neuburg 1740) „stellet vor die aberwitzige Verehrung, so die Japoneser ihren Affter-Götteren erweisen“ “. ${ }^{20}$

Die heidnische Religion der Japaner (Shintoismus und Buddhismus) wird mit dem Bereich des Komischen und Dämonischen in Verbindung gebracht. ${ }^{21}$ In vielen Szenen wird der Glaube der Japaner als Aberglaube gezeichnet und der Lächerlichkeit preisgegeben. So verkauft im Augsburger TITVS-Spiel von 1629 ein gewitzter europäischer Künstler den Japanern „eines seiner Stucken / als einen wunderbahrlichen GOTT für / welcher dann auch ihnen ihres Lebens folgende Jahr und andere Ding weissagt". 22 Besonders auch die Götzenpriester, Bonzen genannt (von jap. bonsō: ,buddhistischer Priester'), erscheinen in negativem Licht. Sie sind überheblich, gierig und nutzen den Heilswunsch ihrer Schutzbefohlenen schamlos aus: In einem TITVS-Spiel (Rottweil 1656) wird berichtet, wie ein Heide namens Mondonus vom Götzenpriester Bagoa sein ewiges Leben erkauft:

Mondonus / welcher von Bagoa dem Bontzen / mit einem Wechsel Brieff / auff das zukönfftige Leben / in den Himmel lautendt / angewisen handtschrifftlich hinder das Liecht geführt / will sein Gelt kurtzumb widerumb herauß haben / weil nun Bagoas nichts als böse Wort außgibt / bezahlt er den betriegerischen Wechselherrn mit barer Müntz und guten Stössen / nimbt das seinig mit Gewalt / deme ohngefahr zween arme Tropffen / so von den Bontzen des Himmels / Armuthalber / schon längst verwisen / zuhilff kommen / und alles in raucher Wehrung erlegen helffen. ${ }^{23}$

18 Unter anderem QUATERNIO | Martyrum Iaponensium (Straubing 1632), I 3. IACOBVS NACAXIMVS (Ingolstadt 1664), II 2. FORTITVDO | IAPONICA (Rottenburg 1665), III 1. BUNGODONI | deß Tyrannen | Grausambkeit (Amberg 1667), II 1. MINAMI GOROZAIMON JOANNES (Feldkirch 1669), II 4. THOMAS Parens, MATTHIAS Frater | IACOBVS ET IVSTVS Filii (Neuss 1673), I 6. PHOEBUS | POST NUBILA (Rottenburg 1697), I 2. FORTITUDO | CHRISTIANA [...] | IN PRINCIPE | MELCHIORE | BUIENDONO (Neuburg 1699), I 2. FORTITUDINIS CHRISTIANAE | IN MELCHIORE | BUJENDONO | [...] TRIUMPHUS (Straubing 1733), I 3-4.

19 TITVS IAPON | Fünffacher aber lebendi- | ger Martyrer (Rottweil 1656), III 3.

20 CLEMENS JAPON | TRAGOEDIA. | Clemens | Ein | Adelicher Ritter | Aus Japon / | Mit seinen Söhnen, | In einem Trauer-Spiel | Auff offentlicher Schau-Bühne | Vorgestellet (Neuburg 1740), I Tanz. - Vgl. Ruprecht Wimmer: Japan und China auf den Jesuitenbühnen des deutschen Sprachgebietes. In: Ruprecht Wimmer und Adrian Hsia (Hg.): Mission und Theater (Jesuitica; 7). Regensburg 2005, 17-58, hier 28.

21 Vgl. ebd., besonders 27-31.

22 TITVS IAPON | TRAGICOCOMOEDIA. Von wundersamer Be- | ständigkeit eines edlen Japonischen Rit- | ters [...] (Augsburg 1629), IV 2.

23

TITVS IAPON (Rottweil 1656), I 5. 
Diese Szene führt nicht allein die Naivität des Heiden Mondonus, sondern auch die Geldgier der Priester vor Augen. Im Diesseits verhaftet, sind sie nicht an Transzendenz, sondern am eigenen Wohlergehen interessiert. Auf die daraus resultierende Gleichgültigkeit gegenüber der armen Bevölkerung verweist ferner eine weitere Szene des Spiels:

PEnulus und Codrus zween guete arme Gesellen erzürnen sich über die Geltgührige Bontzen / welche jhre Seckel spicken / die Armen aber mager herumb gehen / ja hunger sterben lassen. [...] Lassen jhnen [...] Christum mit sambt den Christen wolgefallen / weil dise die Himmel Thür den Armen / dürfftigkeit halber gleich wie die Bontzen nit verriglen. ${ }^{24}$

Um den Einfluss des christlichen Glaubens in Japan zurückzudrängen, schrecken die buddhistischen Priester auch vor Betrug und List nicht zurück. Im Drama Simon | Ein $\mid$ Japonischer Fürst $\mid$ Und $\mid$ [...] Glaubens Held (Köln 1767) schließen die heidnischen Priester sich zusammen, um den Tod des christlichen Thronerben Simon zu bewirken: „die betrügerische Bonzien [hatten] das Heer durch einen falschen Wahn getäuschet [...]: als würde so lang kein Heil in den wafen zu hoffen seyn, bis Simon [der] Krone Prinz aus dem Weg würde geraumet werden". ${ }^{25}$ Der angebliche Orakelspruch erweist sich als falsch, nachdem der Feind auch ohne das Opfer des Simon siegreich geschlagen wurde. Als die Bonzen im , Anschluss vom König verlangen, dass Simon nun als Dankopfer getötet werden soll, erkennt der König die Hinterlist der Priester und lehnt das Gesuch ab. ${ }^{26}$ Daraufhin vergiften die Priester Simon, der auf diese Weise das Martyrium erleidet, nach dem er sich das gesamte Stück über bereits gesehnt hatte: „, [Simon überschicket] seinen starkmütigen Geist dem Himmel zu Marter Krone“. ${ }^{27}$

\subsection{Heidentum und Affekte}

In allen Dramen erscheinen die Heiden zudem als affektgeleitet: Über alle sozialen Schichten hinweg sind Missgunst, Machtgier und Zorn Triebfeder ihrer Handlungen, die in vielen Fällen die Ursache für lokale Christenverfolgungen bilden. ${ }^{28}$ Deutlich kommt diese Affektverfallenheit zum Ausdruck in den Selbstmordszenen heidnischer Christenverfolger, die in einigen Dramen anzutreffen sind. In ihnen wird die japanische Tradition des Seppuku (auch bekannt als barakiri) aufgegriffen also des Suizids durch Einschnitt in den Bauch mit einem Kurzschwert oder

Ebd., V 1.

Simon | Ein | Japonischer Fürst | Und | Siegbekräntzer / Unüberwindlicher | Glaubens Held, | Auf der Dreigekrönten | Schaubühne | Vorgestellt (Köln 1767), Argumentum.

Ebd., IV 2.

Ebd., V 4.

Lediglich in einem Märtyrerdrama (IEMON | INVICTUS CHRISTI MARTYR [Straubing 1661]) ist ein christlicher Hofdiener namens Uxingo Urheber einer Christenverfolgung, da er dem Christen Iemon die Generalsehre missgönnt. Im Laufe des Dramas jedoch überfällt ihn Reue ob der von ihm angezettelten Intrige gegen Iemon. 
Dolch. Diese hoch ritualisierte Todeszeremonie verläuft nach einem strengen und komplexen Protokoll, das unter anderem eine Besinnungs- und Vorbereitungszeit, einen Sekundanten, die Anwesenheit eines Shinto-Priesters sowie eines Protokollanten, die Abfassung eines Todesgedichts und rituelle Kleidung verlangt (Abb. 2).

Ganz anders ist die Darstellung in den Japandramen, die das Seppuku vor dem Hintergrund christlicher Selbstmordkritik deuten. Im Drama TITUS IAPON von 1741 wird diese Todesart in der Figur des intriganten Heiden Miura in actu vorgeführt. Nachdem seine Verleumdungspläne gegen den christlichen Protagonisten Titus gescheitert sind, begeht er nach japanischem Brauch Selbstmord: „Miura aber auf die Nachricht / daß auch der erstgebohrne Sohn TITI hingerichtet worden / brinnet in wüthigen Zorn auf / und nach Japonesischen Gebrauch entleibet er sich selbsten" ${ }^{29}$ Hier erscheint die Seppuku-Tradition folglich in einem deutlich affektgeladenen Kontext und wird in einen wirkungsvollen Kontrast zum Tod der Märtyrer gestellt, die nicht aus Gründen weltlicher Ehre sterben, sondern sich bewusst Gott als Opfer darbringen. Dieser Gegensatz zwischen dem heilsbringenden Tod des Märtyrers und dem unheilvollen Sterben des Heiden wird auch im Drama IACOBVS NACAXIMUS (Eichstätt 1664) thematisiert. Es führt den heidnischen Tyrannen Bungodonus vor, der neben dem Titelhelden Iacobus auch viele andere Christen ein grausames Martyrium erleiden lässt. Von den Rachegeistern dieser verstorbenen Märtyrer geplagt, begehrt er am Ende des Dramas, in jenes Becken mit kochendem Schwefelwasser ${ }^{30}$ geführt zu werden, in dem zahlreiche Christen auf seine Anweisung hin gefoltert wurden und den Tod fanden. Sein Selbstmord ist dem zuvor inszenierten würdevollen Sterben der Märtyrer diametral entgegengesetzt und entbehrt selbst in seiner verzweifelten Unbeholfenheit und Drastik nicht einer gewissen Komik:

Bungodonus laufft erschröcklich auß dem Schwefelbadt hinaus / vermeint schon von dem Fewer verzehrt zusein / verzweiflet derohalben / und sucht alle mitl sich umb das Leben zubringen / unter dem rufft die gerechtigkeit die ienige auß den grebren / so er einmal umbgebracht hat / welche alle wider ihn rach schreien. da er kein hilff mehr wüste / stost er ihm halb mit einem Messer das Herz ab / und wird erschröcklich / theils von ihm / theils von den gespenstern erwürget. ${ }^{31}$

29 TITUS | JAPON | TRAGOEDIA. | Titus | Ein Edler Japoneser (Konstanz 1741), II 6.

Das Eintauchen in Schwefelwasser war eine beliebte Foltermethode in Japan: „Dieses Wasser ist so scharf / und durchdringend / daß es biß auf die Beine das Fleisch verzehrt; ja durch den gantzen Leib dringet" (François Carons und Joost Schouten: Wahrhaftige Beschreibungen dreyer mächtigen Königreiche / Japan, Siam und Corea [...]. Nürnberg 1672. Zitiert nach: Kapitza: Japan in Europa [Anm. 11], 507).

31 IACOBVS NACAXIMVS | CVM FILIIS SVIS IOANNE, | MICHAELE, IGNATIO MARTYRIBVS | IAPONENSIBVS | Tragoedia (Ingolstadt 1664), III 8. 


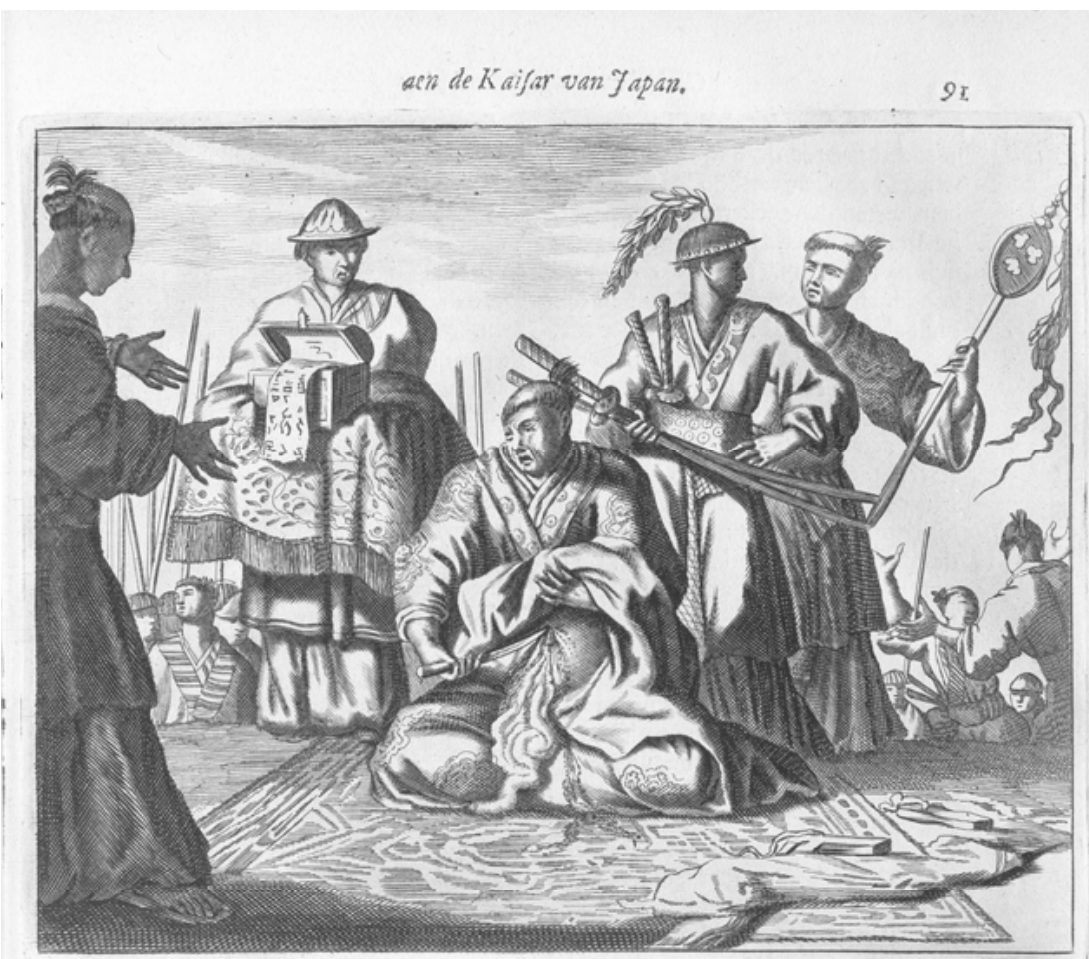

fars wegen. Hydwong den landbou- bende. Defe alle moeften, op een wers meer op te brengen, als'tgeen dag en uur, om de voornoemde mifhooger hand geftelt was. Met dit daed van haer vader of broeder den overfchot verrijkte fich d'edelman. buikfnijden.

't Verdroot eindelijk den boeren: Dit beuls-werkgaetaldustoe. Men Manier dit weshalven klagtig vallen aen den rekent binnen wat tijd de boode ${ }_{d i n\}}^{b a i k-\int n i j-}$

Alebiond' Raed. 't Welk wierd naeuw-keurig 's doodstijding aen de verfte brengen moermom onderfocht: d'edelman fchuldig be- kan: wanneer den nader-gelegene:

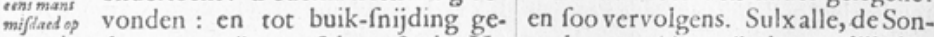
ementhacr doemt met zijn gantfche geflacht. Hy ne hoog zuiden zijnde, gelijkelijk ben. had een broeder in dienft des Koning haer felven op gefeider wijfe moorvan Fingo, twee honderd feven en den. veertigmijlen om de weft vanfedo: Doch foo diep trefte dit ftraf-oefcen oom in Satfuma, twintig mijlen fenen den koopman binnen Ofacca, verder : cen foon by den Koning dat eerlang van hertzeer den geeft Kinocoumy: noch een tweede, ooft- gaf. Zijn dochter wilde infchelijx waerd honderd en tien mijlen buiten haer felf 't leven benemen; maer forgFedo, dienende den Koning CMaf- vuldig bewaerd, ftierf binnen d'elffamme: een derde leggende voor be- Iten dag van honger. Hoc't met de fetteling binnen't Kaifarlijke fot In- wijven van d'overige afliep, had Caquano. Z Zijn jongften foon was ge- ron nietvernomen.

trouwt aen d'cenige dochter eens Cafpar Villela, in zijn brief gefchrevermaerden koopmans tot Ofacca. ven uit Firando, den dertienden Voorts hielden fich twee broeders wijn-maend, des jaers vijfrien hondes edelmans onder 's Kaifars lijf- derd feven en vijftig, getuigt wegens $\mathrm{M}_{2}$ dis

Abb. 2: Seppuku-Darstellung, Kupferstich. In: Arnoldus Montanus: GEDENKWAERDIGE | GESANTSCHAPPEN DER | Oost-Indische Maetschappy | in't Vereenigde Nederland, | AEN DE | KAISAREN van JAPAN [...]. Amsterdam 1669, 91, Wolfenbüttel, Herzog August Bibliothek, A: 211.2 Hist. 20. 


\subsection{Heidentum und Grausamkeit}

Doch nicht allein Aberglaube und Affektverfallenheit, sondern auch barbarische Grausamkeit zeichnet die japanischen Heiden aus. Diese steht vor allem auch in Wort und Bild der gedruckten Martyrologien im Zentrum, wie es beispielsweise die Kupferstiche aus Trigaults DE CHRISTIANIS APVD IAPONIOS |TRIVMPHIS belegen (Abb. 3-6). ${ }^{32}$

Auch viele Missionsgeschichten, die den Jesuitendramen zugrunde liegen, schildern äußerst brutale und unmenschliche Folterpraktiken. Stellvertretend soll hier aus Crasset zitiert werden:

$[\mathrm{M}]$ an [hat] gewisse Rohr mit Schweffel / Wermuth / und anderen stinckenden Sachen angefüllet / denen Martyrern in die Nase gestecket / das Maul verhalten / und dise stinckende Materi am unteren Theil angezündet. Dise Pein ware so grausam / daß dise arme Leuth nicht allein halb ersticket in Ohnmacht verfallen / sondern auch im Angesicht gantz verbrennet worden. Andere wurden mit zugespitzten Rohren in den Leib gestochen / welche dann oft abbrachen / und in der Wunde stecken bliben. Was aber grausam anzuhören [...] ist / daß man wie die Bohrer verfertigte Rohr in den Leib gedrehet / und mit selben das Fleisch heraus gerissen hat. Sie wurden über dises mit Facklen gebrennet / hierauf an Händ und Füß gebunden / in die Lufft aufgezogen / und also mit knottichten Stöcken geschlagen [...]. Die Weiber [...] zu bezwingen / hat man ihre Kinder in ihrer Gegenwart gebraten. ${ }^{33}$

Die jesuitischen Märtyrerdramen führen Folter und Hinrichtung auf offener Bühne vor. Sie konfrontieren den Zuschauer in der Tradition des senecanischen Theaters direkt mit der Grausamkeit, ohne diese in Botenbericht oder Teichoskopie zu vermitteln. ${ }^{34}$ Als eindrückliche Hypertrophie der atrocitas mag die Tragödie Christianomachia Iaponensis (Luzern 1638) gelten. Hier mutiert die Bühne - der Titel (Christianomachia / ,Kampf der Christen') ist Programm - zu einem gewaltigen Kampfschauplatz und präsentiert sechzehn Einzel- und Gruppenmartyrien sowie

32 Trigault gibt auf dem Titelblatt an, sein Werk sei „cum iconibvs Sadelerianis“ erschienen. In der Forschung ist allerdings umstritten, welcher Kupferstecher der Familie Sadeler sich hinter dieser Angabe verbirgt. So formuliert Gabriele Greindl gestützt auf eine Korrespondenz zwischen Trigault und dem Münchner Hof die These, dass Raphael Sadeler d. J. das Werk illustriert habe (Gabriele Greindl: Die Briefe Maximilians I. und Elisabeths von Bayern an den chinesischen Kaiser im Jahr 1617. In: Renate Eikelmann [Hg.]: Die Wittelsbacher und das Reich der Mitte. 400 Jahre China und Bayern. München 2009, 105-111, hier 108), Nicolas Standaert schreibt die Kupferstiche hingegen Raphael Sadeler d. Ä. zu (Nicolas Standaert: An Illustrated Life of Christ Presented to the Chinese Emperor. The History of Jincheng shuxiang (1640) [Monumenta Serica; 59]. Sankt Augustin-Nettetal 2007, 60).

33 Jean Crasset: Außführliche Geschicht | Der | In dem äussersten Welt-Theil | Gelegenen | Japonesischen Kirch [...], Bd. 2. Augsburg 1738, 498.

34 Das frühe jesuitische Drama (zum Beispiel bei Pontanus und Balde) hatte im Rekurs auf Horaz (Ars poetica 182-184) sich zunächst gegen die Darstellung von Grausamkeiten auf der Bühne ausgesprochen. Vgl. zur Gewaltdarstellung auf der frühneuzeitlichen Bühne Arnd Beise: Verbrecherische und heilige Gewalt im deutschsprachigen Trauerspiel des 17. Jahrhunderts. In: Markus Meumann und Dirk Niefanger (Hg.): Ein Schauplatz herber Angst. Wabrnehmung und Darstellung von Gewalt im 17. Jabrhundert. Göttingen 1997, 105-124, hier 113. 


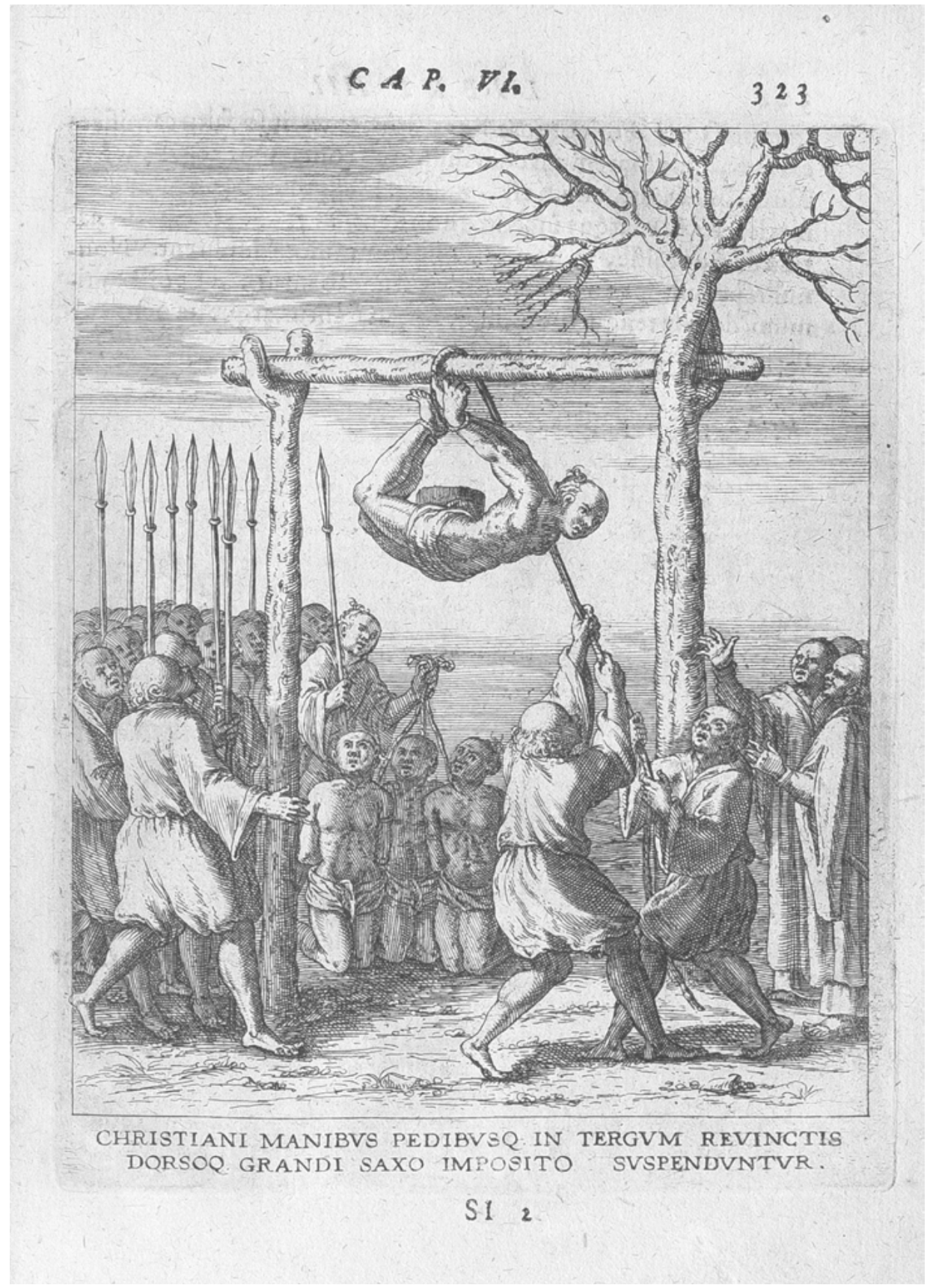

Abb. 3: Martyrium der siebzig Christen in der Hafenstadt Cuchinotzu, Kupferstich. In: Nicolas Trigault: DE CHRISTIANIS APVD IAPONIOS | TRIVMPHIS [...]. München 1623, 323, Wolfenbüttel, Herzog August Bibliothek, A: 197 Hist. 


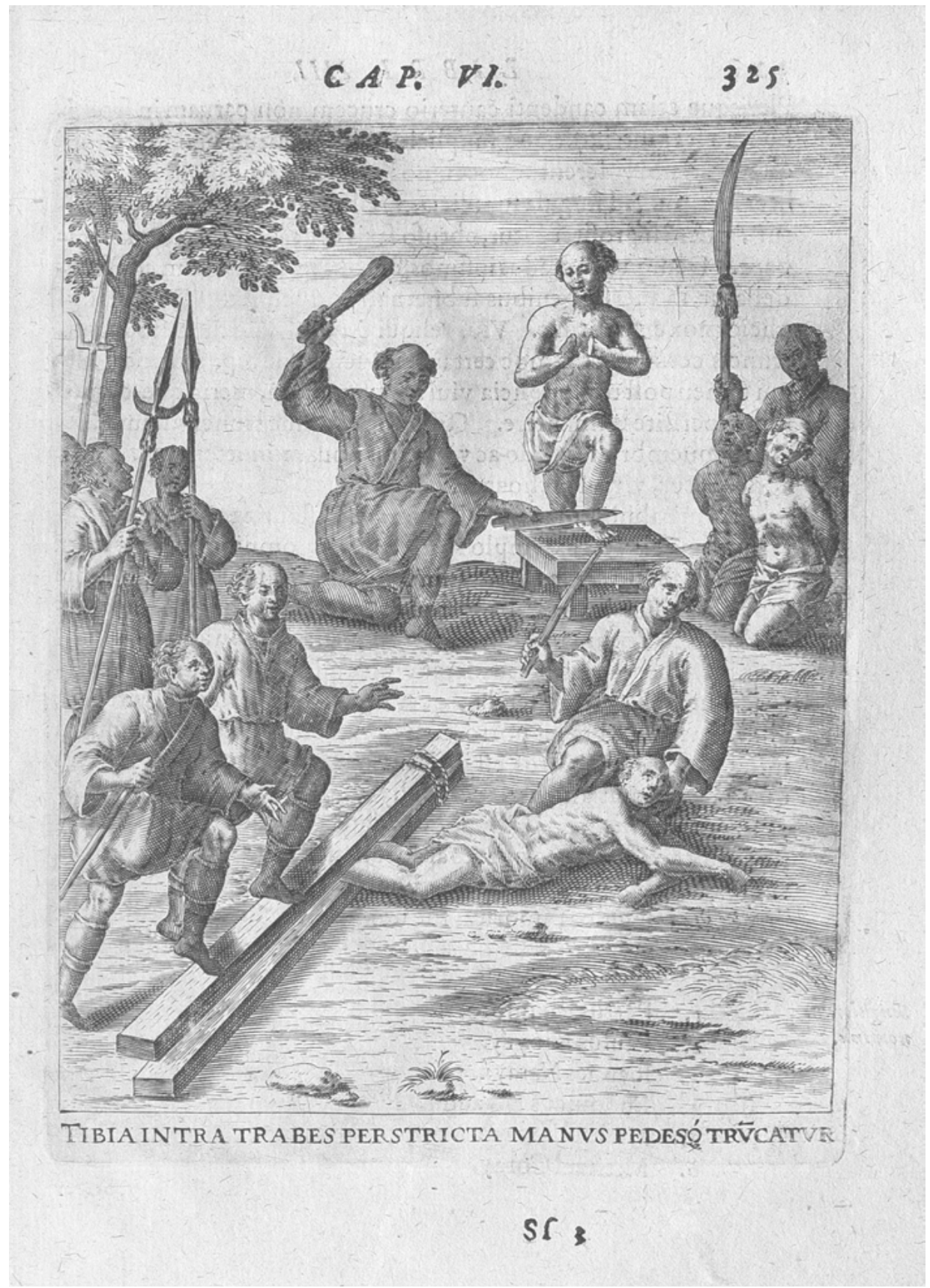

Abb. 4: Martyrium der siebzig Christen in Cuchinotzu (Detail), Kupferstich. In: Nicolas Trigault: DE CHRISTIANIS APVD IAPONIOS | TRIVMPHIS [...]. München 1623, 325, Wolfenbüttel, Herzog August Bibliothek, A: 197 Hist. 


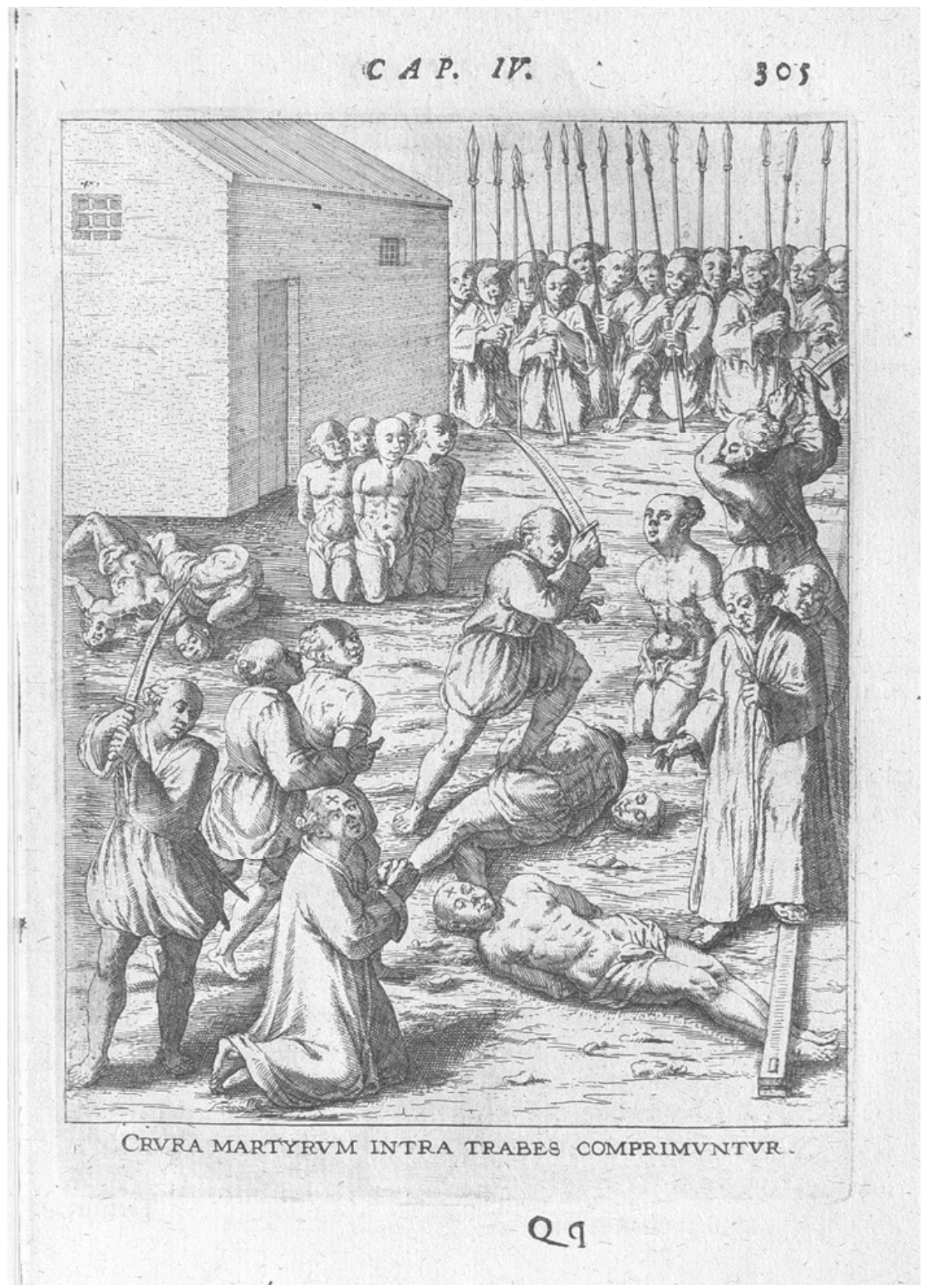

Abb. 5: In Arima werden siebzehn Christen grausam gefoltert, verstümmelt und geköpft, Kupferstich. In: Nicolas Trigault: DE CHRISTIANIS APVD IAPONIOS | TRIVMPHIS [...]. München 1623, 305, Wolfenbüttel, Herzog August Bibliothek, A: 197 Hist. 


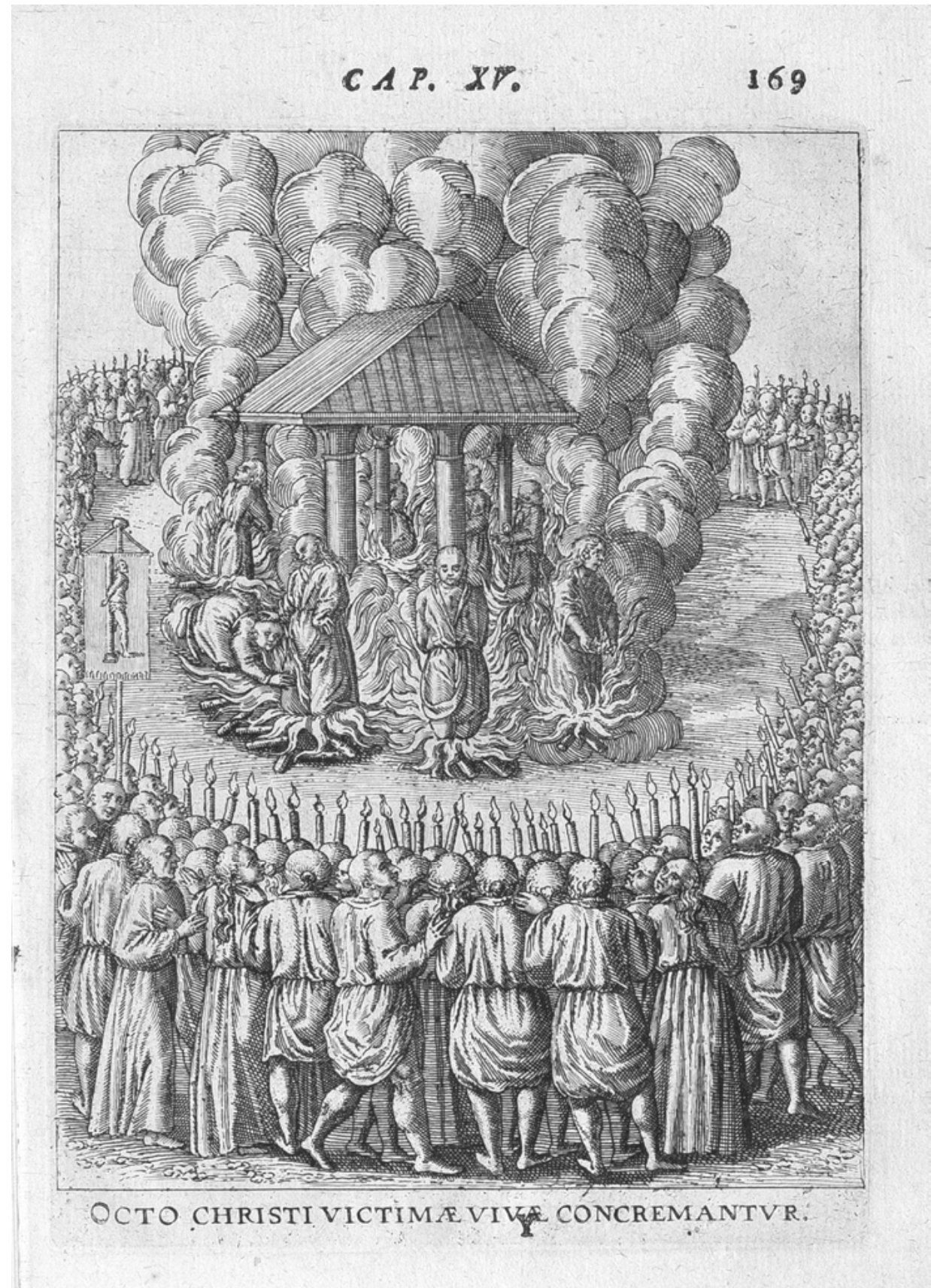

Abb. 6: Acht Christen werden in Arima öffentlich verbrannt, Kupferstich. In: Nicolas Trigault: DE CHRISTIANIS APVD IAPONIOS | TRIVMPHIS [...]. München 1623, 169, Wolfenbüttel, Herzog August Bibliothek, A: 197 Hist. 
zahlreiche Folterungen: Die Christen sollen mit glühenden Kohlen oder in heißen Schwefelquellen zum Glaubensabfall gezwungen werden - diejenigen, die beständig bleiben, werden enthauptet, geröstet, verbrannt oder gekreuzigt: „Benedictus

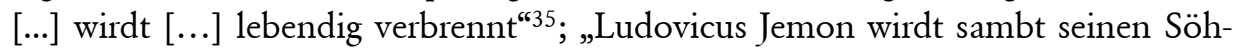

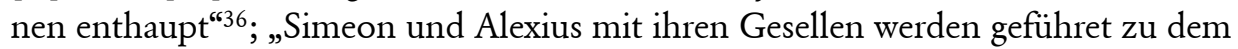
warmen Schweffelbad / und grausamlich damit gepeiniget“37; „Josephus Asoyemon / Iacobus \& Venustus seine Söhn / werden an die Creutz gehäfft / und mit Lantzen durchstochen"38; „Iacobus Cusioye wirdt geführet zum Scheitterhauffen [...] werden auch die Kinder zum Schwerdt hingerissen / un jre Häupter der betrübten Mutter fürgeworffen“39; „Thomae Quichibioye wirdt mit einer hilzenen Säg daß Haupt hinweg genommen. Christophorus laßt sich diß nit schröcken wurdt derwegen durchstochen " 40 . So gewaltig ist der sadistische Erfindungsreichtum der Japaner, dass im selben Drama sogar der Teufel seinem Staunen Ausdruck verleiht: „Der Teuffel verwundert sich uber der Menschen spitz fündigkeit / in erfindung unerhörter grewlicher Marter". ${ }^{41}$ Im Märtyrerdrama IACOBVS NACAXIMVS (Eichstätt 1664) lässt der Statthalter einer Christin sogar die Köpfe ihrer Kinder, die den Märtyrertod erlitten, als eine Art cena Thyestea vorsetzen: „Tonus ladt Agatham zu der daffel / werden ihr aber anstat der speisen auffgetragen die blutige Köpff ihrer Kinder / Welches / da sie gesehen / in ohnmacht gefallen ist / und schier vor schmertzen gestorben". ${ }^{42}$

Diese in den Dramen zentral herausgearbeitete exzessive crudelitas $^{43}$ erfüllt in den jesuitischen Märtyrerdramen gleich mehrere Funktionen. Sicherlich wird durch die Inszenierung der Gewalt das Publikum in der Tradition der ignatianischen Sinnenschau ${ }^{44}$ mit dem Leiden eindrücklich konfrontiert und dadurch

35 Christianomachia Iaponensis, | Das ist | Erschröckliche Verfol- | ung und Blutbadt: | Welches im Jahr Christi 1628. 29. und 30. in Japon | wider die Christen angericht worden (Luzern 1638), III 6.

36 Ebd., III 8.

37 Ebd., IV 4.

38 Ebd., IV 2.

39 Ebd., IV 3.

40 Ebd., IV 4.

41 Ebd., IV 5: „Fatetur orcus, superari se sanguineorum mortalium ingenio.“ Hier ist der lateinische Text im Vergleich zum deutschen noch drastischer, da der Teufel sich nicht nur wundert, sondern sogar eingesteht, vom Erfindungsreichtum der blutgierigen Menschen gar übertroffen zu werden.

42 IACOBVS NACAXIMVS (Eichstätt 1664), III 5.

43 Die auf die Bühne gebrachte brutale Grausamkeit kennzeichnet nicht allein die Jesuitendramen - sie findet sich beispielsweise ebenfalls in den Dramen von Lohenstein und Gryphius, gerade auch im exotischen Umfeld einer Sophonisbe und Catharina von Georgien. Zur Gewaltdarstellung auf der frühneuzeitlichen Bühne: Beise: Verbrecherische und heilige Gewalt (Anm. 34). Zu fragen wäre, inwieweit sich die Grausamkeit japanischer Bühnenfiguren von orientalischen oder europäischen unterscheidet.

44 Die jesuitische Meditation, wie sie in Ignatius von Loyolas exercitia spiritualia präsentiert wird, enthält in der applicatio sensuum, in der geistigen ganzheitlichen Schau mit allen Sinnen, ein theatralisches Element; vgl. Josef Sudbrack: Die Anwendung der Sinne als Angel- 
emotional affiziert. Doch fernab einer nur voyeuristischen Intention ${ }^{45}$ ist die Gewalt in den Dramen Mittel zum Zweck, hebt sie doch den Heroismus der Märtyrer umso stärker hervor. Deren Unschuld kontrastiert mit der Perfidie ihrer Verfolger, ihre Leidensfähigkeit in aller Qual verweist auf den Beistand Gottes, der seinen bedrängten Gläubigen die nötige constantia verleiht. Indem im Martyrium die Zerstörung des materiellen Körpers zur Schau gestellt wird, schärfen die Dramen zugleich das vanitas-Bewusstsein und fungieren als consolatio für ein Publikum, dem die Furcht vor den irdischen Übeln und Nöten genommen werden soll. ${ }^{46}$

\section{Japanische Christen als europäische Helden}

Im Gegensatz zu den Heiden, die in ihren unchristlichen, barbarischen und affektgeleiteten Handlungen deutlich als ,fremd' markiert sind, werden die japanischen Märtyrer in ein dem Publikum vertrautes traditionelles Märtyrermodell eingebunden. Dies geschieht hauptsächlich durch zwei Strategien.

Zum einen reihen sich die Märtyrer in eine chronologische, christliche Heldenfolge ein. Sie werden in Analogie zu biblischen und kanonischen Heiligen gestellt und orientieren sich in ihrer Passion an tradierten (biblischen) Codes. ${ }^{47}$ Vor allem die Chöre schaffen solche Verweissysteme, wenn sie die jeweiligen Märtyrer mit den biblischen Geschichten von Jephtha ${ }^{48}$, Isaak und Jacob ${ }^{49}$ oder dem Martyrium der sieben Makkabäer ${ }^{50}$ verknüpfen. Die Beschreibung einer Szene des Titus Japon-Dramas (Ingolstadt 1657) lautet: „Tito wirdt das Schlacht-Opffer Abrahams zu seinem Beyspill auff dem Berg vorgehalten / desto eyffriger seine drey allerliebste zu dem Todt gutwillig vorgeschickte Kinder / wie auch sich und sein liebste Gemahlin auffzuopffern". ${ }^{51}$ Aber auch die Argumenta erheben die Zugehörigkeit

punkt der Exerzitien. In: Michael Sievernich und Günter Switek (Hg.): Ignatianisch. Eigenart und Methode der Gesellschaft Jesu. Freiburg [u.a.] 1990, 96-119.

Die exzessive Gewalt stellte sicherlich auch ein Faszinosum für das Publikum dar, vor allem wenn genuin japanische Foltermethoden und Hinrichtungspraktiken auf die Bühne gebracht wurden (zum Beispiel das Eintauchen in Schwefelwasser oder die japanische Form der Kreuzigung).

46 Hans-Jürgen Schings: Consolatio Tragoediae. Zur Theorie des barocken Trauerspiels. In: Reinhold Grimm (Hg.): Deutsche Dramentheorien, Bd. 1: Beiträge zu einer historischen Poetik des Dramas in Deutschland. Wiesbaden 1971, 1-44, besonders 22-36.

47 Typische Handlungselemente sind: Weigerung des Märtyrers, einem heidnischen Gott kultische Verehrung zukommen zu lassen, Gefangennahme und Haft, Verhör und Folter (wobei der Märtyrer weder durch Schmeicheleien noch durch Drohungen und Folter vom christlichen Glauben abzubringen ist), Todesurteil, froher Gang zum Richtplatz, Hinrichtung. Ri 11, 29-40.

49 Gen 22, 1-14.

502 Makk 7, 1-42.

51 Titus Iapon | Fünffacher aber lebendiger | Martyrer (Ingolstadt 1657), IV 2. - Diese Parallele findet sich bereits bei Trigault: DE CHRISTIANIS APVD IAPONIOS | TRIVMPHIS (Anm. 4), 228, der vielen der Titus-Periochen als Quelle dient: „Sed prae multis admirabilis mihi videtur neophyti nobilis (Titum appellant) animi magnitudo, quem si quater aut Abraha- 
der japanischen Märtyrer zu einer europäischen Heldengalerie zum Thema. So heißt es im Prolog des Luzerner Spiels TITVS BVCONDONVS von 1721: „Japonia Europae offert Titum Bucondonum fortissimos inter Europae Heroes meritò numerandum \& in templo Gloriae coronandum. "52

Zum anderen werden die Märtyrerfiguren im Verlauf der Dramenhandlung zu milites Christiani stilisiert und dadurch in eine christliche Heldenfolge integriert. Die Jesuiten rekurrieren dabei auf ein Bild, das bereits in der Bibel präsent ist und das Leben eines Christen als Kampf beschreibt. ${ }^{53}$ Die frühchristlichen Autoren, vor allem Tertullian, haben dieses sprachliche Bild verstärkt zur Beschreibung der Märtyrer verwendet und deren Heroisierung somit im Rekurs auf die klassischen militärischen Helden gestützt. Explizit ausformuliert findet es sich in den Dramen beispielsweise in folgendem Chor des Dramas FORTITVDO | JAPONICA (Straubing 1667):

Antonius ein Christ in deme er seine Befreundte suecht / ihres Raths in bevorstehender Noth zupflegen / trifft er Ungefähr der Arimenischen Kirchen Schutz-Engel an: Von welchem er mit den Christlichen Waffen wird angethan / und gestärckt / darauff als ein Ritter Christi behertze / zerreist er das Fürstliche Mandat [i.e. das Mandat gegen die Christen]. ${ }^{54}$

Deutlich erinnert diese Passage an das Bild des kämpfenden Christen der Paulusbriefe, besonders in Eph 6: „Zieht an die Waffenrüstung Gottes, damit ihr bestehen könnt gegen die listigen Anschläge des Teufels!" 55 In den meisten Dramen wird

mum aut alterum Iobum dixero, nihil auxisse mihi videbor“ (sinngemäße Übersetzung: ,Aber vor vielen anderen scheint mir die Geistesgröße des adligen Neophyten (den sie Titus nennen) bewundernswert zu sein, und ich glaube, nicht zu übertreiben, wenn ich ihn einen vierfachen Abraham oder einen zweiten Hiob nenne').

52 TITVS | BVCONDONVS | CHRISTIANAE FORTITVDINIS | Idea. | Daß ist | Titus Bucondonus, | Ein wahres Abbild der Christlichen | Stärcke (Luzern 1721), Prolog (sinngemäße Übersetzung: ,Japan zeigt Europa Titus Bucondonus, der mit Recht unter die tapfersten Helden Europas gezählt und im Tempel des Ruhms gekrönt werden soll'). Die in der Perioche angeführte deutsche Übersetzung lässt die Erwähnung des Ruhmestempels unter den Tisch fallen: „Japonia rühmet sich bey Europa, daß sie an Tito Bucondono einen Mann habe / welcher denen starckmüthigen Glaubens-Bekenneren wohl könne an die Seyten stehen."

53 Beispiele AT: Ijob 7, 1. NT: Eph 6, 11-17. Schon bald wurde das Bild der militia spiritualis von den frühchristlichen Autoren und den Verfassern der Märtyrerakten auf die christlichen Märtyrer übertragen; vgl. Andreas Wang: Der miles Christianus im 16. und 17. Jahrbundert und seine mittelalterliche Tradition. Ein Beitrag zum Verbältnis von sprachlicher und graphischer Bildlichkeit. Frankfurt 1975. Wiebke Bähnk: Von der Notwendigkeit des Leidens. Die Theologie des Martyriums bei Tertullian (Forschungen zur Kirchen- und Dogmengeschichte; 78). Göttingen 2001, 58-76.

54 FORTITVDO | JAPONICA | Das ist. | Christliche Standhafftigkeit dreyer Starck- | mütigen Blut-Zeugen Christi in Japonien | THOMAE FEIBIOYE, JUSTI | Und JACOBI seiner Söhnen (Straubing 1667), II Chorvs.

55 Eph 6, 11; zitiert nach: Deutsche Bibelgesellschaft (Hg.): Die Bibel. Die ganze Heilige Schrift des Alten und Neuen Testaments. Nach der deutschen Übersetzung Martin Luthers. Stuttgart 1984. - In der Christianomachia Iaponensis (Luzern 1638) besitzt auch der Neophyt Xiquibu die Waffen Gottes: „Xiquibu thut sich an mit Geistlichen Waffen“ (III 4). 
die Stilisierung des Märtyrers zum miles Christianus jedoch weniger plastisch vor Augen gestellt. Hier erscheint er als Kämpfer auf zwei Ebenen: Zum einen ist seine Seele Schauplatz des Kampfes zwischen der Stimme Gottes (vox deı) und des Teufels (vox diaboli) - er ficht gegen weltliche Ruhm- und Ehrsucht sowie gegen das eigene Fleisch und dessen Begierden. ${ }^{56}$ Der leibliche Märtyrertod ist letzte Konsequenz dieses Kampfes und gleichbedeutend mit der Erringung des persönlichen Heils.

Über diesen inneren Kampf hinaus jedoch partizipiert der Märtyrer als miles Christianus auch am metaphysischen Kampf zwischen himmlischen und höllischen Mächten, die hinter den konkreten menschlichen Gegnern stehen. Umkämpft ist hier nicht das persönliche Heil des Märtyrers, sondern dasjenige der Welt. Mit seinem Sterben trägt der Märtyrer dazu bei, den Teufel zu schwächen und den Sieg Christi zu antizipieren. Gerade diesen letzteren metaphysischen Kampf machen viele Japandramen in ihrer Handlung sinnfällig: In den Prologen, Chören und einzelnen Szenen schildern sie die Welt als Schauplatz eines metaphysischen Krieges. Als Beispiel sei aus der Perioche zum Spiel IACOBVS NACAXIMVS (Eichstätt 1664) zitiert:

Der Japonische Teuffel beklagt sich höchlich uber die Glückselige sig / unnd waffen / mit welchen der H. Franciscus Xaverius schier gantz Orient Christo bezwungen. Förchtet sich er möchte auch die gewaltige Insul Japon bekriegen; [...] Derohalben gantz verzweifelt ruefft er sein hellische macht herauß / stellt sich in gute postur und schlachtordnung / damit die tugent kein Fueß könne in die Insul sezen. ${ }^{57}$

Die allegorische Kriegshandlung der Eingangsszene liefert hier ein Erklärungsund Deutungsmuster für die Christenverfolgung, bei der hinter den heidnischen Machthabern und Götzenpriestern der Teufel steht. Dieses teuflische Heer wird im weiteren Dramenverlauf in seiner Perversion und Grausamkeit geschildert. Nachdem der Jesuitenmissionar Franz Xaver bei seiner Ankunft in Japan das teuflische Heer vernichtend geschlagen hat, heißt es:

Die Abgötterey ligt in zügen / und will verreckhen; kombt ihr aber zuhilff der Teüffel. Weilandt Königin Elisabeth auß Engellandt / sambt der Ketzerey / welche mit Menschen Blut die Kranckheit zustillen / das einige mitl seye / auß sagten: die Thyranney bringt etliche Menschen Köpff als die beste püllele [i.e. Flaschen]: haltet auch der Abgötterey ein köstliches Pangeth / bey welchem die wilden Thier Taffeldeckher seindt und von Todtenbeinren und Menschen Fleisch getracttirt wird; darauff aber voll und toll / begeben sie sich nach dem Königlichen Hoff alles zuverwürren. ${ }^{58}$

56 Häufige Opponenten in diesem Kampf sind in den Dramen zum Beispiel der amor filiorum und der amor Dei - also die Liebe zu den eigenen Kindern und die Liebe zu Gott. In den Dramen um den Christen Titus, dem wohl beliebtesten Japanstoff, muss dieser seine drei Kinder dem heidnischen Fürsten nacheinander zu Folter und Tod ausliefern, da er seinem Glauben nicht abschwören will. Viele der Titus-Dramen thematisieren die inneren Konflikte, die Titus wegen des fürstlichen Befehls austragen muss.

57 IACOBVS NACAXIMVS (Eichstätt 1664), I 1.

58 Ebd., I 3. 
Inmitten des teuflisch-animalischen Heeres, das sich am grausigen Bankett erfreut, befindet sich die Königin von England, die gemeinsam mit der Ketzerei zum Morden aufruft. In vielen anderen Japandramen sind es die calvinistischen Niederländer, die mit dem Teufel im Bunde stehen und die Christenverfolgungen in Japan initiieren. ${ }^{59}$ Hier wird ein weiteres Mal deutlich, dass die Grenzlinien der Dramen nicht entlang vertrautem Europa und fremdem Japan verlaufen, sondern katholisches Christentum und Heidentum (ob nun buddhistisch oder protestantisch) einander gegenübergestellt sind.

Zusammenfassend lässt sich also feststellen, dass in den japanischen Märtyrerdramen weniger fremde Helden, sondern Helden in der Fremde auf die Bühne gelangen. In der Stilisierung des Märtyrers zum miles Christianus und in seiner Anlehnung an biblische und christliche Helden wird er in ein dem Publikum vertrautes Schema gefügt. Die heidnischen Gegenspieler der Märtyrer erscheinen ebenfalls typisiert als diesseitsverhaftete, affektgeleitete und grausame Diener des Bösen. Kulturelle Eigenheiten wie etwa das Seppuku-Ritual oder bestimmte Foltertechniken dienen dabei der negativen Charakterisierung. Das Corpus der japanischen Märtyrerdramen bietet folglich kein exotisch-japanisches Konkurrenzmodell zur eigenen (europäischen) Heroik. Stattdessen propagieren die Protagonisten das Bild einer katholischen Weltkirche, die sich zwar ethnisch heterogen präsentiert, im Glauben jedoch geeint ist. Damit sind die japanischen Märtyrer letztlich vielmehr milites Christiani als milites Iaponi.

\section{Potenzierte Fremdheit-japanische Märtyrer in der Fremde}

Abschließend sei ein Drama vorgestellt, das im Kontext des ,Helden in der Fremde' innerhalb der Japonica einen Sonderstatus einnimmt, da es die Fremdheit gleichsam potenziert. Das 1670 in Konstanz zur Aufführung gebrachte Drama APOSTASIA | FORTITER PROFUSO | SANGUINE ELUTA stellt dem Publikum die Früchte der jesuitischen Mission in einer neuen Dimension vor Augen. Hier erleidet ein japanischer Christ fernab der Heimat das Martyrium im vom muslimischen Glauben geprägten Afrika. Francesco Sacchinis HISTORIA SOCIETATIS $I E S V$, die der Dramenautor als Quelle verzeichnet, ${ }^{60}$ berichtet von einem japanischen Christen, der ein neues Leben in Afrika beginnen will. Dort konvertiert er zum Islam, leidet jedoch deshalb unter Gewissensqualen. Als ein portugiesisches

59 Das lateinische Argumentum des Eichstätter TITUS CHRISTIANUS-Dramas von 1735 konstatiert: „Dum Heterodoxos, ut Auctores exercitatae in Catholicos tempestatis, in scenam inducimus, non figmentum, sed veritatem historicam proponimus" (sinngemäße Übersetzung: ,Wenn wir die Andersgläubigen als Urheber des Sturms, der gegen die Katholiken hervorgerufen wurde, auf die Bühne bringen, dann tragen wir nicht eine Lüge, sondern eine historische Wahrheit vor').

60 Franciscus Sacchini: HISTORIAE | SOCIETATIS | IESV | PARS QUINTA | SIVE | CLAVDIVS. Tomus prior. Rom 1661, § 398. Der Text ist nahezu wörtlich in das Argumentum der Perioche eingegangen. 
Handelsschiff in den Hafen einläuft, bittet er daher den Kapitän, ihn mitzunehmen und in christliches Gebiet zu bringen. Als der afrikanische König davon erfährt, lässt er dreißig portugiesische Kaufleute des Schiffes gefangen nehmen und droht ihnen mit dem Tod. Daraufhin beschließt der Japaner, sich dem König zu stellen, um ein Blutvergießen zu vermeiden. Am Hof bekennt er sich öffentlich zum Christentum und stirbt nach der Folter den Märtyrertod.

Vor dem Hintergrund der licentia poetica amplifiziert der jesuitische Dramenautor das Geschehen und legt den Schwerpunkt auf den zweifachen Gewissenskonflikt des Apostaten, dem er den Namen Jacobus gibt. Sein Glaubensabfall bei der Ankunft in Afrika hat zur Konsequenz, dass er seinen Status als miles Christianus verliert und den himmlischen Gütern die weltlichen vorzieht. Dies kommt gleich in der Eingangsszene zum Ausdruck, wenn der König ihn seiner geistlichen Waffen entkleidet und stattdessen mit weltlichen Ehren überhäuft („,beraubt ihn der gehabten geistlichen Waffen / behencket ihne an dero statt mit anderen köstlichen

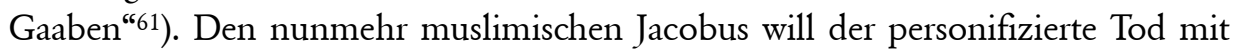
sich führen, wird jedoch von der Divina Providentia daran gehindert: „der Todt zihlet auff ihn / und wurde den unfruchtbaren Baum außgehawen haben / wo nit die Göttliche Fürsehung sich entgegen gesetzt" ${ }^{\text {"62 }}$. Diese schafft damit die Möglichkeit zu Einkehr und Buße: Schritt für Schritt reift in Jacobus die Erkenntnis seiner Sünde, die er mit dem Abfall vom wahren Glauben beging. Christus selbst tröstet ihn in dieser Verzweiflung und schenkt ihm neue Hoffnung: „Jacobus beweinet hertzlich seine Sünd des Abfalls / wird von Christo auß der Verzweiflung in getröste Hoffnung gestellet“. ${ }^{63}$

Diesem ersten Gewissenskonflikt, der ihn zur katholischen Kirche zurückgebracht hat, folgt ein zweiter, der seinen wiedergefundenen Glauben ins Wanken zu bringen droht: Um nicht an einer Feier zu Ehren Mahomets teilnehmen zu müssen, flieht Jacobus zu einem portugiesischen Handelsschiff und bittet den Kapitän, ihn in ein christliches Land zu bringen. Als der König daraufhin seine Herausgabe fordert und andernfalls die Ermordung der Geiseln ankündigt, kämpfen in Jacob Angst und Liebe miteinander: Diese ermutigt ihn zur Beständigkeit im Glauben, jene zum wiederholten Glaubensabfall („die Forcht tringt ihne zum Abfall / die Liebe zur Beständigkeit" $\left.{ }^{64}\right) .{ }^{65}$ Doch auch in diesem zweiten Konflikt bleibt der amor divinus siegreich: In letzter Minute begibt Jacobus sich an den Hof, um die Gefangenen auszulösen und seinen Glauben zu bekennen. Er stirbt, wie im Argumentum beschrieben, einen vorbildlichen Märtyrertod: „In währender

61 APOSTASIA | FORTITER PROFUSO | SANGUINE ELUTA (Konstanz 1670), I 1.

62 Ebd., I 5.

63 Ebd., II 6.

64 Ebd., IV 6.

65 Zugespitzt wird der Konflikt vor den Augen der Zuschauer dadurch, dass in zahlreichen Szenen die Not der Portugiesen geschildert wird, die von der Entscheidung des Jacobus abhängig sind (IV 1; IV 5; IV 2; IV 5). 
Marter widerholet er zum öffteren die zwölff Articul deß Christlichen Glaubens / rüeffte die allerheyligste Namen JESU und Mariae an / und gab darunder seinen Geist auf".66

Das Drama führt dem Zuschauer somit einen radikalen Wandel vor: Jacobus, zu Beginn des Dramas ein Apostat, stirbt am Ende den Märtyrertod. Das Bühnenstück als Warnung vor der Apostasie zu lesen, wie Szarota dies tut, ${ }^{67}$ scheint daher zu kurz zu greifen. Ein Blick auf den Prolog liefert einen Hinweis auf die Botschaft des Dramas: „Mahomet durch Krieg und Gottlosigkeit macht ihm schier die gantze Welt anhängig / wird aber verjagt von beyden Tugenden Lieb und Forcht / welche Christus / der das verlohrne Schäflein suchet / außsändet / daß sie die schlaffende Sünder erwecken ". ${ }^{68}$ Hier wird die doppelte Intention des Dramas deutlich: In Anlehnung an das Gleichnis vom verlorenen Schaf ${ }^{69}$ wird in der Figur des Jacobus vorgeführt, dass die Gnade Gottes dem Menschen eine zweite Chance gewährt ${ }^{70}$ und Gott seine verlorenen Schafe (auch aus dem fernen japanischen Teil seiner Herde) in allen Ecken der Welt sucht.

Zum anderen jedoch wird in der Verbannung Mahomets, die das Dramenende bereits vorwegzunehmen scheint, eine weitere Aussageabsicht deutlich: Das junge Christentum in Japan, das der jesuitischen Missionierung seinen Ursprung verdankt, bezeugt nun seinerseits das Evangelium in der Welt und bringt Frucht. Indem sich Jacobus in potenzierter imitatio Christi für die Kaufleute und zugleich für seinen Glauben opfert, wird er zum Apostel des Evangeliums in der afrikanischen Fremde und trägt dazu bei, den Islam zurückzudrängen. ${ }^{71}$ Gerade mithilfe der gesteigerten Fremdheit (Japaner in Afrika) und ethnischen Vielfalt (Japan, Portugal, Afrika) stellt das Drama die katholische Kirche als Weltkirche dar und

66 Ebd., Argumentum.

67 „Eine echte Warnung vor der Abtrünnigkeit ist dieses Stück: Denn durch die Apostasia gerät nicht nur Jacob selber in Seelennot und stirbt eines schrecklichen Todes, nachdem er sich wieder zu Christus bekannt hat, sondern die Abtrünnigkeit zieht auch die Gefahren anderer nach sich, kann auch für andere todbringend werden." (Elida Maria Szarota: Das Jesuitendrama im deutschen Sprachgebiet. Eine Periochen-Edition. Texte und Kommentare, Bd. 2.2: Tugend- und Sündensystem. München 1983, 2317) Jedoch ist es nicht der Schrecken des Todes, der im Drama überwiegt, sondern der Triumph des Märtyrers. Der These Szarotas, das Martyrium sei als Sühne für die Sünde der Apostasie zu werten (ebd.), kann entgegnet werden, dass sein Opfertod die logische Konsequenz aus der Rückkehr zum Glauben darstellt. Ferner ist es nicht die Apostasie Jacobs, welche die portugiesischen Kaufleute in Lebensgefahr bringt, sondern strenggenommen gerade seine Rückkehr zum Glauben und das damit einhergehende Verlangen, in ein christliches Land zu reisen. APOSTASIA | FORTITER PROFUSO | SANGUINE ELUTA, | ET IN SCENAM PRODUCTA (Anm. 61), Prologus.

69 Lk 15, 1-7.

70 Indem sie seinen Tod verhindert, ermöglicht die Divina Providentia erst die Blutzeugenschaft im Martyrium.

71 Auf diese Funktion verweist auch sein Name (in der Quelle des Dramas ist er namenlos): Unter den Aposteln Jesu befanden sich zwei mit Namen Jacobus (Jacobus, Sohn des Zebedäus, sowie Jacobus, Sohn des Alphäus). 
führt dem Publikum vor Augen, dass einem jeden Katholiken - in der Heimat und in der Fremde - im göttlichen Kampf als miles Christianus eine bedeutende Rolle zukommt.

\section{Abbildungsnachweise}

Abb. 1-6: (C) Herzog August Bibliothek, Wolfenbüttel. 